Original article

\title{
Experiences of the civilian Iranian operating room nurses: A historical survey of the Iran-Iraq war
}

\author{
Mohammadreza Firouzkouhi', Mayumi Kako² ${ }^{2}$ Abdolghani Abdollahimohammad ${ }^{1}$, Ali Zargham-Boroujeni ${ }^{3, *}$
}

(Received: 7 Oct 2015; Accepted: 23 Dec 2015)

\begin{abstract}
Background and Purpose: Upon centuries, wars have taken over countries due to theadvancement of sophisticated warfare,causingserious injuries among soldiers. Nurses are directly involved in preoperative and postsurgical patient care. One of the most remarkable contributions of the Iranian operating room nurses was to provide medical care for wounded soldiers in field hospitals during the Iran-Iraq war. This study aimed to explore the experiences of civilian operating room nurses infield hospitals at the frontlines during the Iran-Iraq war.

Methods: This study was conducted using historical research methodology and oral history method throughin-depthinterviews with civilian nurses engaged inoperating rooms during the war.Participants were selected via snowball sampling. This study investigated nursing practice in operating rooms as recountedby 16 civilian nurses who served in field hospitals inthe Iran-Iraq war during 1980 1988.

Results: This study had six descriptive themes focusing on the experiences of nurses engaged in operating rooms during theIran-Iraq war, and the results were obtainedin a narrative style. The main themes extracted from the study were"establishment of medical centers in the frontlines", "organization of emergency medical teams", "establishment of operating rooms", "nursing duties inthe operating room", "documentation of medical interventions", and "vulnerability of nurses in the operating room".

Conclusion: The findings of this study will significantly enhance the current knowledge regarding operating room nursing practiceduring the Iran-Iraq war, enabling a greater understanding of this particular medical experience.
\end{abstract}

Keywords: Historical research, Iran-Iraq war, Operating room nurses, Operating room, Oral history

\section{Introduction}

The Iran-Iraq war, which occurred during 19801988 , is considered as one of the most monumental events in the Iranian history accounting for uncompensable human loss for both parties (1).

Within a few decades before the war, advancement in warfare industry heightened the risk of death in battlefields. As such, these changes convinced militaries to establish medical facilities, especially operating rooms, in the vicinity of the frontlines in order to have access to immediate treatment forinjuredtroops, particularly in case of surgeries. In addition to surgical facilities, the medical technology and nursing skills in this regard had to be improved in order to cover the demand during the critical period of war (2).

Nurses engaged in operating rooms havedifferent responsibilities depending on the conditions of the unit. In non-military hospitals, medical events are

\footnotetext{
${ }^{1}$ Faculty of Nursing \& Midwifery, Zabol University of Medical Sciences, Zabol, Iran

${ }^{2}$ School of Nursing and Midwifery, Flinders University, Australia

3,* Corresponding author: Nursing and Midwifery Care Research Center, Faculty of Nursing and Midwifery, Isfahan University of Medical Sciences, Isfahan, Iran. Email: zargham@nm.mui.ac.ir
} 
usually predictable, controllable and less stressful, whereas military hospitals have tumultuous environments. During the war, nurses are faced with excessive pressure due to the increased amount of duties in operating rooms, and contributions of nurses are as essential as those of anesthetists and surgeons to the effective management of the patients (3).

In military hospitals, surgery is mainly required for the injuries caused by weapons and war craft. Under favorable circumstances, injured patients are treated by the military medical staff. However, demand rises due to the extent of the conflict during wars, and non-military medical staff may bedeployed to war zones for professional assistance. This might be unexpectedforcivilian medical personnel who lack the adequate experience for serving in the battlefields; therefore, they need to adapt themselves to the new conditions within the least possible time (4).

In the eight-year war between Iran and Iraq (1980-1988), medical activities in surgery rooms of field hospitals were considered vital, especially with the ongoing development of medical unit facilities as the war continued. This resulted in the provision of more efficient and professional medical services with respect to surgeries (5).

By deploying highly skilled medical teams at different sections of field hospitals, contributionsof these groups to the welfare of the wounded troops increased. These medical teams were able to assist in numerous surgical operations within the shortest amount of time. Moreover, availability of professional medical teams was considered essential to helping the injured soldiers (6).

Due to certain limitations during the early years of the Iran-Iraq war, non-military nurses faced remarkable challenges as to cover the medical demand in field hospitals. Nevertheless, they soon gained the required military nursing experiences, which significantly reduced the mortality rate among seriously wounded battle forces (7).

During the war, initial treatmentswere carried outinthe frontlines and continued at the emergency unitsbased in the battlefields. If necessary, the injured would betransferred to field hospitals, and after triage, decisions would be made for further treatments. If surgery was a necessity, it would be performed immediately, and normal procedures continued afterwards at secondary medical centers. Nurses played a pivotal role in all these processes, especially in operating rooms. This resulted in a fundamental change in the general view towards nursing practice and later enhanced nursing professionalism in Iran (8).

In this regard, Biedermann et al. (2002) conducted a qualitative study in order to assess the experience of operating room nurses in Australia who were deployed at the Vietnam War, stating that operating roompractices played a critical role in the reduction of mortality rates and improvement of medical servicesduring the war (9).

Historical research methodology offers a considerable body of knowledge in qualitative studies. This methodology is usedto collect the experiences of individuals about a historical event, as well as to discover social interactions between different variables. This approach helps researchers to focus on unknown political processes, social nature, individuals, and events in a specific timeline. Furthermore, researchers attempt to judge an event based on the characteristics of the concerning period and associated processes (10).

Today, investigation of the experiences of wartime nurses and their participation in field hospitals and emergencies during military missionshas drawn the attention of many researchers since it yields invaluable information in the field of nursing (11). This study aimed to survey the nature of nursing practice among non-military nurses engaged in operating rooms at field hospitals during the IranIraq war. Thorough analysis of the findings will expand the knowledge of operating room nurses and motivate them to pursue a professional attitude in their career.

\section{Materials and Methods}

This study aimed todescribe the experiences of operating room nurses participating in the Iran-Iraq war in Isfahan, Iran in 2012. Common experiences of civilian nurses serving in the field hospitals and emergency departments formed the framework of this study. 
Historical researchmethodology and oral history method were used to collect the experiences of the nurses engaged in the operating rooms of field hospitals (12, 13). In 1948, Professor Allan Nevins from Colombia University proposedthe oral history method as the process of recording the recounted memories of authorized professionals. This method involves the orderly collection of living people's first-hand reports and reflecting on their personal experiences. In recent years, this approach has largely contributed to the recording and documentation of nursing experiences. Combined with other qualitative research methods, the oral history method helps to enrich available sources with respect to the full range of activities performed by nurses $(14,15)$.

A widely acknowledged bone of contention in historical methodology has been the procedure through which a credible and trustworthy narrative is produced from the collected data. Special techniques, which may be used in this approach, include interviews, direct observation, analysis of official and unofficial documentations, review of personal or collective journals, evaluation of personal and public domain photoarchives, and more recently, digital photographs, and audio and videotaperecordings (14).

Oral history method in historical studies is also considered as a reliable approach since, as in the present research, it provides an opportunity for the participants to express their feelings, thoughts, and memories, as well as to furnish their journals, photos, and notes for the purpose of the study (11). Moreover, the information gathered from secondary sources regarding the historical context of events shapes the research format depending on the description of the involved individual and location of the events (10).

For selecting the participants, the inclusion criteria of the present studywere as follows: 1) registered nurses; 2) engagement in the operating rooms related to fieldhospitals; 3 ) participation in military missions; 4) voluntary participation in the war; 5) ability to recall the memories and experiences of the warand 6) consent to take part in interviews.

All selected participants met the inclusion criteria and had taken part in most of the major military operations as field hospital nurses. Since we had no access to the lists of nurses who served during the Iran-Iraq war in non-military agencies, a purposive sample was drawn via snowball sampling (16).

In total, 16 nurses who met the inclusion criteria were enrolled in this study. Informed consent was obtained from all participants before the interviews. After collection and analysis of the data, obtained through each interview, successive respondents, suggested by the previous participants, were selected. This helped the researchers to extend the range, depth, and scope of the achieved information.

Initially, one adequately informative nurse who met the inclusion criteria was interviewed, and afterwards, he introduced other nurses to be interviewed. It is noteworthy that some of the interviews were carried out purposefully to meet the objectives of the study.

Interviews were conducted using three main questions, whichformed the interviewing process for larger studies and generated the data required for the current study. The interview questions were as follows:

Can you describe your tasks in the operating room during the war?

Can you elaborate on your duties regarding the preparations of the injured patients for surgeryupon admission?

Can you compare the early and final days of the war in terms of operating room tasks?

The last question was particularly relevant to the subject of the study; however, all the obtained responses were fully analyzed.

Participants were asked to describe their experiences regarding the medical performance in the operating rooms of field hospitals and elaborate on the effects of these experiences on their daily lives and professional nursing career.

This study mainly intended to raise the discussion of relevant experiences of nurses during the war. Time and locationof the interviews were determined with the agreement of the participants. Each participant was interviewed twice or more, and the interviews lasted between 45-90 minutes (one hour on average). All the interviews were recorded by a voice recorder and transcribed for data analysis. 


\section{Data analysis}

Collected data were analyzed using the methods proposed by Firouzkouhi and Zargham. Initially, the researchers listened to all audiotapes several times in order to become fully aware of the content, tone, and feeling of the participants. In this process, significant words, phrases, sentences, and paragraphs were extracted from each transcription. Each new piece of information was compared with previously extracted items (17).

In the first step, the interviews were coded separately in order to create the initial themes of the study. Afterwards, using constant comparison, the initial codes were grouped based on the similarities to form different categories. To enhance the credibility of analysis, data were validated through the verification of the findings with the participants to ensure that they recognized the content as a true representation of their narratives $(17,18)$. Collection and analysis of data continued until data saturation.

Credibility, dependability, confirmability and transferability were used as the main measures to judge the scientific rigor. To determine the credibility, which is defined as long-term involvement with the research subject, ongoing observation was performed. To do so, the researcher would randomly select a few interviews from the files of other coresearchers, analyze and compare the content with his findings, and finally, review the results with the related participant.

To determine dependability, the researcher asked another colleague to transcribe and analyze the interviews. Moreover, the researcher used an external audit and bracketing to achieve data confirmability. To increase the transferability, the researcher selected participants with the highest variation (19).

\section{Ethical considerations}

In this study, ethical codes were taken into accountin accordance with the enactment of the Ethics Committeeof Isfahan University of Medical Sciences, and the study was initiated after the ethical approval. Moreover, informed consent was obtained from all the nurses prior to the study. Each participant was assigned a number, and anonymity of the participants was guaranteed.

\section{Results}

In this study, 16 male volunteer nurseswho were members of different emergency teams during the war were interviewed.Mean age of the nurses at the war was 21.2 years, and mean age at the time of the study was 41.2 years. Among the participants, $60 \%$ were permanent personnel of operating rooms, and $40 \%$ worked in this unit in case of emergency. In addition, $80 \%$ of the nurses were experts in clinical and managerial nursingand performed civilian clinical activitiesbefore the war.All the participants had actively participated in the most important military battles without previous wartime nursing experience.

Narrations given by the participants were divided into two periodic phases of 1980-1982 and 19831988. Moreover, six themes were extracted from the interviews under the category of "operating room practice", as follows:

1) establishment of medical centers in the frontlines; 2) organization of emergency medical teams; 3) establishment of operating rooms; 4) nursing duties in operating rooms; 5) documentation of medical interventionsand 6) vulnerability of nurses in operating rooms. All these themes were presented in a narrative style.

\section{Experiences of the operating room nurses during 1980-1982}

When the Islamic Republic of Iran was attacked by Iraq, the Iranian forces were not prepared at all. The Islamic Revolution had just succeeded, and the foundations of the state were being established. The headquarters of the armed forces, as well as their hierarchical organizational structures, were undergoing major changes, and national security at the borderlines was at substantial risk.

With the breakout of war between the countries, civil medical centers and hospitals in the region were struck down, and many were closed down. In the wake of the war, there were insufficient health care personnel in the provinces close to borderlines. Nevertheless, the health centers and hospitals in 
majorcities continued their operations with high enthusiasm despite thelimited number of nursing staff in order to function like field hospitals.

The actual field hospitals were established in sturdy buildings that could survive heavy bombardments in order to help the injured troops. Medical tasks in these hospitals were performed by the fewremaining medical staff, including operating room nurses. Operating rooms were the ordinary spaces in the buildings, which were altered to suit surgical procedures.

Due to the distance between the frontlines and hospitals, the number of casualties and deaths drastically increased while transferring the injured troops. At this point of the war, there were not enough educated nurses deployed at field hospitals, and operating room nurses were not considered as medical team members. However, as can be seen in the second narration, the number of operating room nurses and educatednursing staffincreased dramatically in the war zones and field hospitals after the establishment of operating rooms.

In this regard, participant number seven remarked:

"... There was a hospital in Kurdistan province (west of Iran), which was always under attack. The hospital was big with large operation rooms, but we could not use this hospital because the enemy targeted it with missiles continuously.There were four rooms in the basement of this hospital, in which even a stretcher could pass in with difficulty. Nevertheless, nurses did everything to help the injured even under the hardest of circumstances."

One of the themesin this study wasthe "establishment of medical centers in the frontlines". As the war went on, hospitals began to operate on three levels: field hospitals equipped with operating rooms, city hospitals far from the war zone, and specialized city hospitals far from the warzone.

In this regard, participant number three said:

“...Seriously injured soldiers needed immediate surgery. At the beginning, there was no special space to be used as the operating room, but then, field hospitals were established near the frontline, and professional hospitals were also available in the nearest cities. These specialized hospitals were equipped with radiology units, laboratories, and operating rooms. The field hospitals were fully equipped as well, so that there was mostly no need to send the injured soldiers to secondary hospitals in case of the need for surgery. All necessary care was provided at the field hospitals, and only in case special treatments were required, the injured would be transferred to other hospitals."

As the war continued, primary medical centers, such as field emergency units and hospitals, were established in order to perform the assigned tasks. Field hospitals were more central as they covered both field emergencies and aid posts. Furthermore, emergency services and tasks, as well as small and major operations, were performed for the injured troops in these medical centers (5).

During the war, treatment stages followed changeable patterns. In this period, medical centers were developed under specific conditions with different structures.

Based on the extracted data from the interviews regarding the challenges against health care and strengthening of the medical staff in urban areas near the war zone, the Relief and Treatment Center (Emdad \& Darman office) were established in order to coordinate the medical personnel. This organization branched out at the provincial level. Through this system, necessary information was transmitted to the sub-structures of the provinces, so that they could arrange the transfer of nursing staff to the war zone within the least amount of time.

Another theme in this study was the organization of emergency medical teams. Emergency medical teams consisted of specialized surgeons, general practitioners, nursesand other medical staff. Naturally, nurses outnumbered other medical personnel in field emergency departmentsand they even performed minor surgical operations. The main duties of nursing staff in field hospital operation rooms were triage, circular scrub, anesthetic assistance, recovery room care, and even accompanying the patients during their transfer.

As far as efficiency wasconcerned, since they were near the war zone, field hospitals made remarkable contributions to the life-saving operations for the injured troops. On the other hand, since initial medical units were exposed to a higher risk of 
hostilities, fewer lives could be saved during the early years of the war.

In this regard, participant number 16 narrated:

“...I think that we followed an evolutionary pattern in the structures of medical centers. We began medical practice in tents, timber shacks, and tinplatesheetshacks that were then covered with metal sheets. After some time, these spaces were replaced by reinforced concrete structures. For instance, operating rooms in Imam Reza Hospital of Mashhad were surrounded and covered with reinforced concrete. Additionally, hospital authorities developed square and rectangular precast, concrete, box-shaped portable structures in Imam Sajjad Hospital."

According to these narratives, it could be concluded that field hospitals started to operate more efficiently as the war progressed. Moreover, operating rooms in the hospitals in the vicinity orfar from the frontline offered valuable services that saved many lives reducing the rate of mortality and disabilities caused by war injuries.

\section{Experiences of the operating room nurses during 1983-1988}

As the Iranian forces made advances to free the occupied regions, the distance between the frontline and hospitals with operating rooms increased. Therefore, new fieldhospitals equipped with operating rooms were built near the war zone.Based on available secondary sources, establishment of fieldhospitals equipped with operating rooms resulted in the cooperation of more than 300,000 medical personnel (mainly operating room nurses) during the eight years of war. This significantlyreduced the rate of mortality among the injured troops, and othereffective services were providedas well (5).

The third theme of this study focused on the establishment of operating rooms. With the advancement of the military system, operating room nurses became more decisive in performing their duties at this medical section. At the beginning of the war, nursing practices were not recognized as such; however, as surgery rooms in field hospitals started to operate, the role of nurses engaged at these units became more important.
In this regard, participant number four stated:

“... One interesting point during the war was that nurses and their practices were not known to all; nurses were considered as expert rescuers (Imdadgar) or medical assistants. However, this concept changed as the field hospitals began their operations with fully specialized staff. For instance, when surgeons became aware of our nursing skills, they asked us to assist them in the operating room or take care of the injured soldiers in the recovery room."

According to the documents in secondary sources,while numerous military missionswere under way to reclaim the occupied regions,operating rooms had an outstanding performance to provide the necessary care for the injured troops. For instance, WalFajr-4 operation, which occurred in the North West of Iran, was considered as a major military operation due to itsspecific features and obstacles. In this war zone, three fieldhospitals with 12 operating departments were active, offering medical services for as much as 5,742 injured troops, many of whom were saved through surgeries (20).

Another example is Wal Fajr-10, which was a major military mission at the Balambo heights in the west of Iran in a battlefield area of $1200 \mathrm{~km} 2$. Lack of proper access roads, mountainous features of the landand vastness of the area were major obstacles during this military operation. Nevertheless, five fieldhospitals with 25 operating departments were established in this zone in order to provide medical services for thousandsof wounded soldiers. The majority of these troops were transferred to war-free zones after receiving proper treatments (21).

In total, 173,823 wounded soldiers were treated in field hospitals during the eight years of war between Iran and Iraq, and at least 7,617 patients underwent surgical operations in 17 fieldhospitals. These patients were transferred to hospitals with higher levels of equipment to receive special care (5).

During the war, operating rooms and anesthesia procedures were of paramount importance in reducing the mortality rate and enhancing the health of the injured troops. In this regard, the function of operating room staff has been described as extraordinary by several reports. Establishment 
of field hospitals equipped with operating rooms not only helped the wounded, but it also offered practical opportunities for non-military nurses, which resulted in the effective treatment of the patients. Although operating rooms appear to serve similar purposes, their function changes drastically during critical situations.

In this regard, participant number 10 stated:

"... Operating rooms in field hospitals were fully equipped with facilities and apparatuses similar to those of big hospitals. The wounded troops were brought to the emergency section first. After triage, the shift physician would examine the patient and decide whether to transfer him to level two or three hospitals, or if the patient needed immediate surgery, the nurses prepared them for operation. Some of the major surgical operations, such as blood vessel surgeries, internal surgeries, hepatic rupture, spleen, abdominal viscera, and orthopedic surgeries, were conducted efficiently in field hospitals."

Another theme in the present study was focused on the duties of the nursing staff in operating rooms. Nurses are the second main contributors in operating rooms after surgeons, compensating for any lack of trained medical staff.

According to our findings, performance of the nurses was remarkable in mobile medical teams where there were excessivecasualtiesand a poor chance of saving the lives of the injured. Nurses had to take significant medical measures (e.g., intubation, chest tube insertion, intravenous catheterization) to keep the wounded troops alive outside the hospital. Interview results of this study indicated that nursing experience in the battlefield was mainly the result of working in operation departments and recovery rooms, as well as with mobile medical teams. In addition, short distances between the frontline and operating rooms wereconsidered as a contributing factor to effective nursing practice in the war zone.

In this regard, participant number 16 said:

"...We did all the medical tasks, such as the preparation of injured troops, shaving of thesurgery site, blood reservation, sending blood samples to laboratory, and informing the surgeon of the condition of the patient when there was another surgery in progress. Moreover, some of the operating room nurses performed as assistantsurgeons; they completed the last stitchesand took care of the patients during recovery."

As secondary sources, previous studies conducted in this regard have confirmedthe pivotal role of safe and facilitated operatingrooms of field hospitals in the reduction of patient transfer time to three hours. For instance, in the battle of al-Faw, patient transfer time reduced to less than one hour after the establishment of Imam Sajjad Hospital(22).

In war zone hospitals, some of the surgical operations were likely to last for $2-3$ complete days, while most of the operations lasted for 2-3 hours on average. However, blood vessel surgeries and laparotomy could last for more than three hours. Investigation of the logs found in the operating rooms of Fatemeh Zahra and Ali-ibn-Abitalib field hospitals during Wal Fajr-8and Karbalay4-5 military operations revealed that on average,103 surgeries were conducted per day in these hospitals. These two hospitals were equipped with eight operating rooms each. If transfer of patients to the surgery bed took 10 minutes, each medical operation would last for an average of 101 minutes (22).

In an interview, one surgeon claimed that they were given only 10 minutes of rest between the surgeries. As such, non-stop function of surgeons, operating room nurses and other medicalstaff has been recorded as 48-72 hours during specific military missions (22).

According to the literature, laparotomy (30\%) and orthopedic surgeries (15\%) accounted for the highest rate of medical operations during the war. In some cases, abdominal injuries were so complicated that if not operated onimmediately, they couldlead to the death of the patient. Furthermore, blood vessel grafting was reported in 373 cases in order to prevent amputation.

According to statistics, pneumothorax treatment via chest intubationwas successful in 1,301 cases, which caused a significant reduction in the mortality rate during the war. Medical services and contributions of the field hospitals during the war saved $50 \%$ of acutely injured soldiers who might have died without immediate surgeries and treatments (5). 
In this regard, participant number sixremarked:

"... At the frontline, most of the injuredsoldiers required surgery. When a wounded soldier was brought in, he would be examined by a team of specialist surgeons, and then, the patient was assigned to a specific specialist for immediate treatment. Our nurses were always ready to help the surgeon in all types of medical operations. Operating room work was very serious, and there was no time to rest. In some cases, we worked for 3-4 days with 2-3 hoursof sleep per day."

According to the findings of this study, even open-heart surgery and other rare surgerieswere conducted in fieldhospitals during the war.

In this regard, participant number 10 , who closely witnessed a medical operation, stated:

"... There was one emergency case of ruptured jugular vein and aorta, which was operated on successfully. Once we performed an open-heart surgery due to the rupture of pericardium, the patient would bekept in the recovery room for 24 hours and then, sent to a second-level hospital for further treatments."

Another extracted theme from the interviews in this study focused onthe documentation of medical interventions in operating rooms, which could not be performed successfullydue to massive casualties during the war. However, operating room nurses used intuitive methodsto fulfill this task.

In some cases, a tag would be pinned to the clothes of the patient to indicate his status, and sometimes, this tag would be placed in a plastic bag to be transferred to secondary hospitals with the patient. However, these tags were likely to smash, become blood stained, or go missing during the transfer. In the case of surgery, a medical file was prepared to be transferred with the patient, which could also go missing during the transfer considering the large number of patients and heavy road traffic. Drawbacks in the documentation of patient information led to several problems, such as mixed-up priorities, mistreatment, or sometimes even death. Perhaps, inefficient patient data transfer was one of the main causes of high mortality rates during the war.

The next theme worth mentioning was the vulnerability of operating room nurses during the war. In the Iran-Iraq war, the military and nonmilitary medical staffs were not safefrom the damages caused by chemical warfare. Soldiers were frequently exposed to varioustoxic chemical agents, which could infect nurses and other medical staff in operating rooms as well.

In this regard, participant number eight said:

“... During the WalFajr-8 military mission, a wounded soldier with abdominal cuts and mustard gas intoxication was brought to Fatemeh Zahra fieldhospital. Although we were dressed in special ant-chemical outfits, upon his entry to the operating room, the space became polluted immediately with no time for us to wear masks. The worst thing was thatthe ventilation system of the hospital had spread the polluted air around the placeinfecting so many medical staff, including the operating room personnel. Therefore, the medical staff had to be evacuated immediately."

During the war, due to the substantial military and civiliancasualties, operating rooms in the first- and second-level hospitals played a pivotal role in saving the lives of battlefield forces. This phenomenon has been registered with honor in archived files of the Iran-Iraq war. It should be noted that this victory cost the lives and lifetime health of many nurses after the war.

\section{Discussion}

During the Iran-Iraq war, nurses were able to make long-term contributions to this profession through practicing their expertise in field hospitals. Furthermore, establishment of fully equipped operating rooms in thesehospitals duringthe second half of the war and assignment of non-military nurses resulted in the effective treatment of the injured troops and significant reduction of the mortality rate in this period.

In the field hospitals at the frontline, treatments were provided so completely that there was no need for the transfer of most of the wounded patients to second-and third-level hospitals. This was due to the gradual advances in medical facilities, equipment efficiency, staff professionalism, and surgical 
operations in field hospitals. These notions were explained by one of the main themes of this study (establishment of medical centers and operating rooms in the frontlines).

In one study, it was stated that the value of medical services provided by operating room nurses was first recognizedin the World War I, when medical units were established and equipped atthe frontlines, deeming the deployment ofoperating room nurses necessary for providing health care and reducing the mortality rateamong battlefield forces. These findings are in line with the results of the present study (23).

Both world wars had a remarkable effect on the notion androle of nursing practice, particularly operating room nursing. With the advancement in warfare technology, medical staff and facilities, especially in the surgery department, had to improve in order to compensate for the substantial number of injured soldiers during different wars. Today, operating room nursing is considered as one ofthe most crucialprofessional nursing skills in medicine (3).

In the current study, one of the main themes was the organizationof emergency medical teams, in which surgeons and nurses cooperated within a group to provide the most effective patient care. In these teams, medical professionalsexamined multiple traumatic injuriesin field hospitals and decided whether the patient required urgent surgery or could be safely transferred to better-equipped hospitals. Such interventionswere able to save the lives of many soldiers during the war.

With respect to the reduction of mortality rate, the following are some facts proving the importance of operating rooms in field hospitals: World War II $(29.3 \%)$, the Korean War (26.3\%), and the Vietnam War (19\%). In this regard, anatomic studies conducted on the victims of the world wars have indicated that $15-20 \%$ of the deaths would have been prevented if first-aid medical services were provided in time. Furthermore, if medical and surgical services were available at shorter distances, the mortality rate would have dropped below 70\% (24).

In the Korean and Vietnam wars, rapid transfer of the wounded soldiers to operating rooms was reported to reduce the mortality rate significantly, while in the War in Afghanistan, delayed transfer of the injured troops was reported to increase the mortality rate (25).

Another theme in this study focused on the duties of operating room nurses during the war.In the IranIraq war, nurses had to perform a variety of medical duties, such as the preparation of patients before and after surgery, preparation ofmedical equipment, scheduling of surgeries and supervision of the patients duringrecovery. Moreover, due tothe lack of adequate medical personnel, including surgeons and anesthetists, nurses had to assist anesthetists and other medical professionals.

The study conducted by Biedermann et al. (2002) focused on the fact that deployment of nurses mainly initiated with the outbreak of wars. According to their findings, duties of operating room nurses, facilities, and equipments were similar in general. It was also stated that although the Australian military nurses were mostlywithout operating room training, they were able to adapt to the conditions of the region, which offered inexperienced nurses abundant learning opportunities (11).

In another study, McGarvey et al. (2000) described a wide range of medical duties for nurses during wars. They believed that due to the high rate of casualties, as well as thelack of medical equipment and operating room personnel in war zones, nurses were faced with monumental challenges in fulfilling their responsibilities. Nursing tasks range from the management of injured patients, preparation of the surgery room, and assistance of other medical personnel in the operation room. This finding was consistent with the results of the current study (3).

Another extracted theme in the present study focused on the vulnerability of nurses in the operatingroom. Evidently, nurses are not protected against the risks and threats associated with war zones. They might become exposed to aerial and ground bombardments, as well as chemical agent intoxication. Nevertheless, their humanistic act disregards the circumstances of war. Soldiers can seek shelter in specified concrete bunkers or protective embankments, while operating nurses cannot postpone or stop their duties. Furthermore, nurses may be at the riskof explosionscaused by the pieces of cluster bombs remaining in the body of the 
injured soldiers.

In one research in this regard, battlefield conditions were described as extremely threatening for wartime nurses. As for living circumstances, several restrictions may influence the normal life of nurses, such as extreme weather conditions, inconvenient accommodation, and unsuitable welfare. In addition, war zone nurses have to wear protective gears for their own safety, which could appear as an obstacle in providing health care for the patients (26).

In another study, Schwam (1998) indicated that factors such as surgery room environment and dealing with injured patients suffering from multiple traumas are considered as harsh working conditions for wartime nurses, which may lead to psychological complications later in life. On the other hand, the stress caused bythe management of injured patients and vulnerability of the operation rooms to bombardments are known as constant risks to the well-being of war zone nurses. These findings were consistent with the results of the present study (27).

According to the results of the current study, establishment of operating rooms in the field hospitals and efforts of the nursing staff in these sections played a pivotal role in the reduction of mortality rates during the Iran-Iraq war. Selfsacrifice and commitment of these health care professionals saved the lives of many brave soldiers during the critical time of war.

One of the limitations of this study was lack of access to military nurses and documents with regard to the function of operating rooms in the field hospitals of the battlefield.

\section{Conclusion}

According to the results of this study, nurses, as the largest group of medical staff, were able to serve in several settings adapting their professional practice to the circumstances of the war. One of the main tasks performed by nurses was participation in operating room procedures, which lasted for long hours covering patient care both before and after emergency surgeries.

Valuable experiences have been recorded in the Iranian nursing history. During the postwar period, these health care professionals were active and influential in the successful execution of heart surgeries and transplants. Furthermore, they participated in the formation ofexpert nursing teams, later nurturing the profession of nursing in our country.

The findings of this study also highlight some aspects of the nursing profession, which should be taken into account in military nursing preparation programs, including the vigilance of medical authorities and nursesin critical situations to be of assistance to the nation. Results of the current study could be used in future research regarding the roleof nurses and preparation of nursing curriculum to identify the challenges of this profession in the time of crisis.

\section{Conflicts of interest}

None declared.

\section{Author's contributions}

M Firouzkouhi and A Abdallahimohammad collected and analyzed the data and prepared the draft of the paper. A Zargham-Boroujeni and M Kako evaluated and supervised the entire process of study.

\section{Acknowledgements}

We appreciate the participants for sharing their experience because without their cooperation it wasn't possible to accomplish this study. we would also like to thank the Isfahan University of Medical Sciences for the funding contribution.

\section{References}

1. Tavernier P. The UN secretary-general: attitudes and latitudes. In: The Iran-Iraq War: the politics of aggression. Rajaee F, editore. Florida: University Press of Florida; 1993. P. 167-82.

2. Rowley DI. The management of war wounds involving bone. J Bone Joint Surg Br 1996; 78(5):706-9. 
3. Mcgarvey HE, Chambers MG, Boore JR. Development and definition of the role of the operating department nurse: a review. J Adv Nurs 2000; 32(5):1092-100.

4. Hinsley DE, Rosell PA, Rowlands TK, Clasper JC. Penetrating missile injuries during asymmetric warfare in the 2003 Gulf conflict. Br J Surg 2005; 92(5):637-42.

5. Araghizadeh H, Haidarpoor A, Frasatkish R, Mola SR. The role of field hospital in providing medical care and reducing mortality in troops. Kowsar Med J 2001; 6(2):139-46.

6. Wang TL, Chen HT, Chang H. Hospital preparedness for weapons of mass destruction incidents: an initial assessment. Ann Disaster Med 2004; 2(2):74-8.

7. Betts-Symonds G. Major disaster management in chemical warfare. Accid Emerg Nurs 1994; 2(3):122-9.

8. Hemmings L. Vietnam memories: Australian army nurses, the Vietnam war, and oral history. Nurs Inq 1996; 3(3):138-45.

9. Biedermann N. Experiences of Australian Army theatre Nurses. AORN J 2002; 75(2):335-40.

10. Lewenson S, Herrmann EK. Capturing nursing history: a guide to historical methods in research. New York: Springer Publishing Company; 2008. P. 23.

11. Biedermann N, Usher K, Williams A, Hayes B. The wartime experience of Australian Army nurses in Vietnam, 1967-1971. J Adv Nurs 2001; 35(4):543-9.

12. Miller-Rosser K, Robinson-Malt S, Chapman Y, Francis K. Analysing oral history: a new approach when linking method to methodology. Int J Nurs Pract 2009; 15(5):475-80.

13. Perks R. The oral history reader. United Kingdom: Psychology Press; 1998.

14. Janesick VJ. Oral history for the qualitative researcher: choreographing the story. London: The Guilford Press; 2010.

15. Sommer BW, Quinlan MK. The oral history manual.
London: Rowman Altamira; 2009.

16. Pilot D, Beck CT. Nursing research: principles and methods. Philadelphia: Lippincott Williams \& Wilkins; 2004. P. 232.

17. Firouzkouhi M, Zargham-Boroujeni A. Data analysis in oral history: A new approach in historical research. Iran J Nurs Midwifery Res 2015; 20(2):161-4.

18. Firouzkouhi M, Zargham-Boroujeni A, Nouraei M, Yousefi $\mathrm{H}$, Holmes $\mathrm{C}$. The wartime experience of civilian nurses in Iran-Iraq War, 1980-1988: an historical research. Contemp Nurse 2013; 44(2):225-31

19. Thomas E, Magilvy JK. Qualitative rigor or research validity in qualitative research. J Special Pediat Nurs 2011; 16(2):151-5.

20. Ghanjal A, Sadri Arhami A, Basam SM. Rescue and Transportation experiences of medical department of Sepah in Valfajr 4 operation. J Mil Med 2003; 5(2):91-8.

21. Haj Ahadi ST, Navidi AA, Abolghasemi H, Mohebbi HA. Review of experiences in during sacred defense: valfajr 10 operation. J Mil Med 2002; 4(2):75-80.

22. Zafarghandi M. It was very hard to injure a side with 5 persent chance of being alive. East New 2011; 6(1):20-1.

23. Poe D, Bubb DM, Freeman LK. Implementation of the RN first assistant role. AORN J 1997; 65(1):32-41.

24. Bellamy RF. Death on the battlefield and the role of first aid. Mil Med 1987; 152(12):634-5.

25. Ling GS, Rhee P, Ecklund JM. Surgical innovations arising from the Iraq and Afghanistan wars. Ann Rev Med 2010; 61:457-68.

26. Kelly J. Battlefield conditions: different environment but the same duty of care. Nurs Ethics 2010; 17(5):636-45.

27. Schwam K. The phenomenon of compassion fatigue in perioperative nursing. AORN J 1998; 68(4):642-5. 